\title{
Effect of magnesium on blood pressure
}

\author{
T DYCKNER, P O WESTER
}

\begin{abstract}
Twenty patients receiving long term diuretic treatment for arterial hypertension (18 patients) or congestive heart failure (two patients) received magnesium supplementation as aspartate hydrochloride $15 \mathrm{mmol} /$ day for six months. Both systolic and diastolic pressures decreased significantly, by a mean of $12 / 8 \mathrm{~mm} \mathrm{Hg}$. No significant changes were recorded in plasma or urinary electrolytes except for magnesium, 24 hour urinary volumes, or body weight after treatment.

The effect of magnesium on blood pressure may be direct or through influences on the internal balance of potassium, sodium, and calcium.
\end{abstract}

\section{Introduction}

Changes in plasma concentrations and the total body content of electrolytes, particularly sodium and potassium, influence blood pressure in experimental animals, normotensive subjects, and hypertensive patients..$^{1-3}$ In patients with hypertension and in their normotensive relatives a genetic defect in the handling of electrolytes has been suggested by some investigators. ${ }^{45}$ Extensive studies on experimental animals have shown that disturbances of the metabolism of magnesium may have profound effects on the contractile state of vascular smooth muscle and thus on blood pressure. ${ }^{6}$ Furthermore, thiazides, which are commonly prescribed to treat arterial hypertension, induce major changes in both the external and internal electrolyte balance, ${ }^{7-10}$ and magnesium influences the relation between extracellular and intracellular potassium. ${ }^{78}$

We carried out a study designed to investigate the effects of magnesium supplementation on electrolytes in patients receiving

\footnotetext{
Department of Internal Medicine, University Hospital, S-901 85 Umeå, Sweden

T DYCKNER, MD

P O WESTER, MD, head of department

Correspondence to: Professor P O Wester.
}

long term diuretic treatment for hypertension or congestive heart failure, or both. Some remarkable changes in blood pressure occurred, which we report here.

\section{Patients, and methods}

Thirty nine ambulatory patients receiving long term treatment with diuretics for hypertension or congestive heart failure, or both (and who had been receiving such treatment for over one year) were assigned to the study. Twenty patients (16 women, four men; mean age $62 \cdot 2 \pm S D 4 \cdot 2$ years) were randomised to receive treatment with magnesium. Eighteen of these patients had hypertension (six World Health Organisation grade I, 12 grade II) and four had congestive heart failure (both New York Heart Association grade II). Two patients had both hypertension and congestive heart failure (World Health Organisation grade II and New York Heart Association grade II, respectively, in both cases). The duration of hypertension was between two and 30 years (mean $9 \cdot 7 \pm 6 \cdot 8$ years), and the duration of diuretic treatment ranged from one year six months to 25 years (mean $8.3 \pm 5.5$ years). Thirteen of the hypertensive patients were receiving bendrofluazide $2.5 \mathrm{mg} /$ day, four hydrochlorothiazide $12.5 \mathrm{mg} /$ day, and one mefruside $25 \mathrm{mg} /$ day. The patients with congestive heart failure alone were receiving bendrofluazide $2.6 \mathrm{mg} /$ day (one patient) and frusemide $40 \mathrm{mg} /$ day (one). The two patients with both hypertension and congestive heart failure were receiving bendrofluazide $40 \mathrm{mg} /$ day and frusemide $40 \mathrm{mg}$ twice daily. All patients received potassium supplementation. None of the patients was receiving treatment with other agents known to influence the metabolism of magnesium.

On admission to the study the patients were seen twice at an interval of two to three days. Blood pressure and heart rate were recorded with the patient supine after 30 minutes' rest and in the standing position by a specially trained nurse. The blood pressure recordings were obtained with an ordinary sphygmomanometer, and diastolic pressure was recorded at the disappearance of the Korotkoff sounds. The blood pressures obtained at the second initial visit were used in the protocol. Weight was determined. Blood samples for analysis of concentrations of sodium, potassium, chloride, carbon dioxide, magnesium, calcium, phosphorus, uric acid, creatinine, and total protein were taken as well as 24 hour urinary samples for analysis of excretion of sodium, potassium, and magnesium. Urinary volumes were recorded.

The patients continued their diuretic treatment but received supplementation with magnesium aspartate hydrochloride $15 \mathrm{mmol} /$ day (365 mg magnesium or $3689 \mathrm{mg}$ magnesium aspartate hydrochloride/day), corresponding to the recommended daily intake. After one month a new set of blood samples was taken and blood pressure 
determined as on admission. After six months of treatment the procedure carried out on admission was repeated. Skeletal muscle biopsy specimens were also taken on admission and after six months. Results will be published separately.

The patients randomised to the control group consisted of 10 women and nine men (mean age $67.8 \pm 4$ years). Seventeen patients had hypertension (two World Health Organisation grade I, 15 grade II) and five had congestive heart failure (four New York Heart Association grade II, one grade III). Three of the patients had both hypertension (World Health Organisation grade II) and congestive heart failure (two grade II, one grade I). The duration of diuretic treatment ranged from one to 20 years (mean $6 \cdot 1 \pm 4 \cdot 5$ years). Eight patients were receiving bendrofluazide $2.5 \mathrm{mg}$ /day, three hydrochlorothiazide $12.5-25 \mathrm{mg} /$ day, three chlorthalidone $25-50 \mathrm{mg} /$ day, and five frusemide $40-80 \mathrm{mg} /$ day. All patients received potassium supplements, and none was taking any treatment known to influence metabolism of magnesium. Sampling procedures were the same as for the other group. The control patients continued their treatment unchanged throughout the study.

Sodium, potassium, chloride, phosphorus, carbon dioxide, and creatinine concentrations were analysed by a conventional autoanalyser technique, while magnesium concentrations were determined by atomic absorption spectroscopy. Student's $t$ test for paired observations was used to assess differences before and after six months.

\section{Results}

Blood pressure-In the treatment group 19 of the 20 patients showed a decrease in blood pressure. In three patients the magnesium dosage had to be reduced to $5-10 \mathrm{mmol} / \mathrm{day}(122-244 \mathrm{mg}$ magnesium or 1230-2760 mg magnesium aspartate hydrochloride/day) because of low blood pressure and dizziness. In three other patients the thiazide dosage was reduced. Despite these therapeutic changes both supine and standing blood pressures had fallen significantly $(p<0.001$ and $\mathrm{p}<0.05$, respectively) after six months' treatment with magnesium (table). There was no significant difference in heart rate before and after treatment. In the control group no significant differences were recorded in blood pressure before and after six months' treatment (supine pressure $154 \pm 26 / 90 \pm 11 \mathrm{~mm} \mathrm{Hg}$ before and $154 \pm 28 / 86 \pm$ $13 \mathrm{~mm} \mathrm{Hg}$ after; standing $152 \pm 27 / 91 \pm 10 \mathrm{~mm} \mathrm{Hg}$ before and $154 \pm 27 / 89 \pm 12 \mathrm{~mm} \mathrm{Hg}$ after).

Plasma electrolyte concentrations showed no significant differences after six months' treatment in the patients who received magnesium (table) and the controls.

Urinary electrolytes-Urinary samples were not obtained from the controls. In the treatment group potassium excretion was unchanged after magnesium supplementation while excretion of sodium and magnesium had risen slightly (table).

Other variables-Twenty four hour urinary volumes and body weight showed no significant differences after treatment (table).

\section{Discussion}

More than 4500 years ago it was realised that excess dietary sodium could influence and harden the pulse. ${ }^{11}$ Later, the

Mean $( \pm S D)$ blood pressure, plasma electrolyte concentrations, and urinary electrolyte excretion before and after six months of treatment with magnesium

\begin{tabular}{|c|c|c|c|}
\hline & Before & After & $\begin{array}{l}\text { Significance } \\
\text { of difference }\end{array}$ \\
\hline $\begin{array}{l}\text { Blood pressure }(\mathrm{mm} \mathrm{Hg}) \text { : } \\
\text { Supine } \\
\text { Standing } \\
\text { Heart rate (beats } / \mathrm{min}) \\
\text { Plasma electrolyte concentrati }\end{array}$ & $\begin{array}{c}152=20 / 93: 11 \\
145=17 / 93: 13 \\
76 \div 13 \\
\text { ions }\end{array}$ & $\begin{array}{c}140=15 / 85 \div 7 \\
139=18 / 87 \div 10 \\
75+11\end{array}$ & $\begin{array}{l}p<0.001 \\
p<0.05\end{array}$ \\
\hline $\begin{array}{l}\text { Potassium }(\mathrm{mmol} / 1) \\
\text { Magnesium }(\mathrm{mmol} / 1) \\
\text { Sodium }(\mathrm{mmol} / 1) \\
\text { Calcium }(\mathrm{mmol} / \mathrm{l}) \\
\text { Chloride }(\mathrm{mmol} / 1) \\
\text { Creatinine }(\mu \mathrm{mol} / 1)\end{array}$ & $\begin{array}{rl}3 \cdot 56 & : 0 \cdot 29 \\
0 \cdot 76 & 0 \cdot 08 \\
139 \cdot 6 & \pm 2 \cdot 44 \\
2 \cdot 43 & \pm 0 \cdot 10 \\
99 \cdot 1 & \pm 2 \cdot 7 \\
77 & \pm 13\end{array}$ & $\begin{array}{c}3.62 \div 0.29 \\
0.78 \div 0.06 \\
139 \cdot 4 \div 2.61 \\
2.39 \pm 0.13 \\
100 \cdot 1+3.6 \\
82+13\end{array}$ & $\begin{array}{l}\text { NS } \\
\text { NS } \\
\text { NS } \\
\text { NS } \\
\text { NS } \\
\text { NS }\end{array}$ \\
\hline $\begin{array}{l}\text { Urinary electrolyte excretion: } \\
\text { Potassium }(\mathrm{mmol} / 24 \mathrm{~h}) \\
\text { Sodium }(\mathrm{mmol} / 24 \mathrm{~h}) \\
\text { Magnesium }(\mathrm{mmol} / 24 \mathrm{~h}) \\
\text { Urinary volume }(1 / 24 \mathrm{~h}) \\
\text { Body weight }(\mathrm{kg})\end{array}$ & $\begin{array}{rl}85.4 & \pm 37 \cdot 7 \\
174.5 & 70 \cdot 2 \\
4 \cdot 15 & \pm 1.69 \\
1.62 & 0.78 \\
79 \cdot 0 & \pm 15 \cdot 6\end{array}$ & $\begin{array}{l}83 \cdot 5 \pm 33 \cdot 4 \\
187 \div 76 \cdot 2 \\
5 \cdot 67 \pm 2 \cdot 49 \\
1 \cdot 65+0.78 \\
79 \cdot 5 \div 15 \cdot 9\end{array}$ & $\begin{array}{l}\text { NS } \\
\text { NS } \\
\text { NS } \\
\text { NS } \\
\text { NS }\end{array}$ \\
\hline
\end{tabular}

Conversion: SI to traditional units-Potassium: $1 \mathrm{mmol} / \mathrm{l}=1 \mathrm{mEq} / \mathrm{l}$. Magnesium:

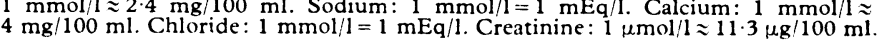

observation was made that blood pressure was considerably $\underset{\sim}{\square}$ lower in communities with a low dietary salt intake compared with those with a high intake. No correlation was found, $\varrho$ however, between salt intake and blood pressure or between $c$ exchangeable sodium and blood pressure within the populations $\frac{\rho}{\bar{S}}$ studied. ${ }^{12}{ }^{13}$ In some studies patients with hypertension, and even their normotensive relatives, were shown to have an increased cellular sodium content, possibly depending on a genetic defect in the transport of electrolytes across cell membranes. ${ }^{4}$ It was then suggested that a combination of this genetic defect and $a$ high dietary salt intake was required to produce high bloods pressure. ${ }^{14}{ }^{15} \mathrm{~A}$ resetting of the renal balance between theo natriuretic effect of blood pressure and the pressure raising $\underline{\underline{ }}$ effects of sodium retention has also been proposed.1617

Potassium may also play a part in regulating blood pressure, $\overrightarrow{\mathrm{D}}$ partly because it influences the metabolism of sodium and partlyo because of effects of its own. Both acute and chronic increases in potassium concentrations lower blood pressure, possibly through. an increase in the activity of Na-K-ATPase and thus in the $\overrightarrow{-}$ transport of electrolytes over the cell membrane. ${ }^{18}$ Extracellularo potassium stimulates $\mathrm{Na}-\mathrm{K}-\mathrm{ATPase}$, which requires magnesium음 for adequate function. ${ }^{19}$ In a recent study on patients with mild. to moderate hypertension potassium supplementation without 0 changes in salt intake resulted in a significant reduction in blood pressure by $4 \%$, or $6 / 4 \mathrm{~mm} \mathrm{Hg} .{ }^{20}$

In our study a significant decrease in blood pressure of. ${ }^{\infty}$ $12 / 8 \mathrm{~mm} \mathrm{Hg}$ was achieved with magnesium supplementation. $\vec{\circ}$ Apart from being a necessary activator of Na-K-ATPase, $\neq$ magnesium is also a calcium antagonist. A decrease in mag-음 nesium leads to increased cellular calcium concentrationsand vasoconstriction. ${ }^{6}$ Magnesium may also have a direct effect ${ }_{\vec{C}}$ on vascular smooth muscle. ${ }^{6}$ In a clinical study in 73 randomly selected subjects not receiving diuretics or other pharmacological ${ }^{\Phi}$ agents influencing the metabolism of magnesium Petersen et al $\overrightarrow{0}$ found an inverse correlation between serum magnesiumç concentrations and blood pressure. ${ }^{21}$

The effects of diuretics on electrolyte metabolism should also be considered. In the long term thiazides may give rise to potassium and magnesium deficiencies and an increased cellularo sodium content, all of which in turn result in increased cellular

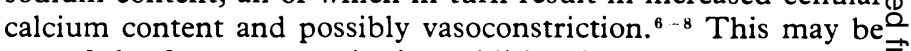
one of the factors necessitating additional treatment to controlo blood pressure adequately in some patients after long term diuretic treatment. The blood pressure lowering effects of thiazides have been estimated to be around $15 / 8 \mathrm{~mm} \mathrm{Hg}$ in several studies of untreated hypertensive patients. ${ }^{22}$ In our study of patients already receiving diuretics an additional reduction of $12 / 8 \mathrm{~mm} \mathrm{Hg}$ was achieved with magnesium supplementation. These results indicate that treatment with magnesium should be considered in arterial hypertension at least as an additional ${ }_{0}^{\circ}$ treatment in patients already receiving diuretics.

\section{References}

${ }^{1}$ Addison WLT. The use of sodium chloride, potassium chloride, sodium bromide, and potassium bromide in cases of arterial hypertension which $\mathbb{O}$ are amenable to potassium chloride. Can Med Assoc $\mathcal{F} 1928 ; 18: 281-5$. N ${ }^{2}$ Louis WJ, Tabel R, Spector S. Effects of sodium intake on inherited $\underset{\sigma}{\sigma}$
hypertension in the rat. Lancet 1971;ii:283-6.

${ }^{3}$ Meneely GR, Battarbee HD. High sodium-low potassium environmento and hypertension. Am $\mathcal{f}$ Cardiol 1976;38:768-85.

4 Henningsen NC, Mattson S, Nosslin B, Nelson D, Olsson O. Abnormal whole body and cellular (erythrocytes) turnover of ${ }^{22} \mathrm{Na}$ in normotensive relatives of probands with established essential hypertension. Clin $\mathrm{Sci}$ 1979;5, suppl: $321-4$.

${ }^{5}$ Henningsen NC, Olsson O, Marrson S, Nosslin B. Whole body measure-尺 ments of sodium in first degree relatives of patients with sustained essential $\mathbb{Q}$ hypertension. Eur f Nucl Med 1982;7:225-8.

${ }^{6}$ Altura BM, Altura BT. Role of magnesium ions in contractility of blood vessels and skeletal muscles. Magnesium Bulletin 1981;1a:102-14.

7 Dyckner $T$, Wester PO. The relation between extra- and intracellular $\frac{O}{0}$ electrolytes in patients with hypokalemia and/or diuretic treatment. Acta Med Scand 1978;204:269-82.

${ }^{*}$ Lim P, Jacob E. Magnesium deficiency in patients on long-term diuretic therapy for heart failure. $\mathrm{Br} M e d \mathcal{F} 1972$;iii :620-2. 
9 Edmonds CJ, Jasani B. Total-body potassium in hypertensive patients during prolonged diuretic therapy, Lancet 1972;ii:8-12.

${ }^{10}$ Ericsson F, Carlmark B, Eliasson K. Erythrocyte and total body potassium in primary hypertension. Acta Med Scand 1981;109:439-44.

1 Veith I, translated from Huang $\mathrm{Ti}$ Nei Ching Su Wen, $2600 \mathrm{BC}$. The yellow emperor's classic in internal medicine. California: Berkeley University Press, 1967.

12 Simpson FO. Salt and hypertension: a sceptical review of the evidence. Clin Sci 1979;5, suppl: 463-80.

13 Pickering GW. Salt intake and essential hypertension. Cardiovascular Reviews and Reports 1980;1:13-7.

14 Frics ED. Salt, volume and prevention of hypertension. Circulation 1976; $53: 589-95$

${ }^{15}$ Dahl LK. Salt intake and hypertension. In: Genest J, Keiw E, Kuchel O, eds. Hypertension, pathophysiology and treatment. New York: McGraw Hill, 1977:548-59.

${ }^{16}$ Borst JGC, Borst-de Grus A. Hypertension explained by Starling's theory of circulatory homeostasis. Lancet 1963; i:677-82.
17 Brown JJ, Lever AF, Robertson JIS, Schalekapm MADH. Pathogenesis of essential hypertension. Lancet $1976 ; \mathrm{i}: 1217-9$.

18 Paller MS, Stuart LL. Hemodynamic effects of alterations in potassium Perspectives in Hypertension $1982 ; 4$, suppl III :20-6.

${ }^{19}$ Skou JC. The influence of some cations on an adenosine triphosphatase from peripheral nerves. Biochim Biophys Acta 1957;23:394-414.

${ }^{20}$ MacGregor GA, Smith SJ, Markandu ND, Banks RA, Sagnella GA. Moderate potassium supplementation in essential hypertension. Lancet $1982 ;$ ii :567-70.

${ }^{21}$ Petersen B, Schrell M, Christiansen C, Transbøl I. Serum and erythrocyte magnesium in normal elderly Danish people. Acta Med Scand 1977;201 : $31-4$

${ }^{2}$ Cransten WL, Juel-Jensen BE, Semmence AM, Handfield-Jones RPC, Forbes JA, Mutch LMM. Effect of oral diuretics on raised arterial pressure. Lancet 1963;ii:966-70.

(Accepted 31 March 1983)

\title{
Exocrine function of testis with germinal testicular tumour
}

\author{
M A S JEWETT, J V THACHIL, J F HARRIS
}

\begin{abstract}
Semen collected immediately before or soon after therapeutic unilateral orchidectomy from 86 men with germinal tumours of the testis was analysed. The mean sperm count was $65.6 \pm$ SEM $10.3 \times 10^{6}$ per ejaculate. This was significantly different from that in a control population, in whom the mean was $165.2 \pm 12.9 \times 10^{6}$ per ejaculate. The difference appeared to be due to a subpopulation of 32 patients with counts of $20 \times 10^{6}$ per ejaculate; the distribution of counts in the remaining patients was similar to that in the controls.

The cause of this abnormality of exocrine function is unknown: it may either be due to the tumour or its treatment, or both, or, alternatively, it may predate the events of the malignant transformation, possibly even acting as an inducing or promoting factor.
\end{abstract}

\section{Introduction}

Dramatically improved survival of patients with germ cell testicular tumours has focused attention on other criteria for outcome of treatment. ${ }^{1}$ Most patients are of reproductive age so that preservation of fertility is important. Treatment is often multidisciplinary with surgical procedures, including unilateral orchidectomy and retroperitoneal lymphadenectomy, plus abdominal irradiation or systemic combination chemotherapy, or both. Each modality affects potential fertility. ${ }^{2}$ Less well understood is the state of spermatogenesis in these patients

Department of Surgery (Urology), The Wellesley Hospital, University of Toronto, Ontario, Canada

M A S JEWETT, MD, FRCS(C), associate professor

J V THACHIL, MD, FRCS(C), Gordon Richards fellow of Ontario Cancer Society

J F HARRIS, PHD, assistant professor

Correspondence and requests for reprints to: Mr M A S Jewett, Suite 206, 160 Wellesley St E, Toronto, Ontario, Canada M4Y $1 \mathrm{~J} 5$. before treatment. ${ }^{3}$ The occasional detection of a tumour during investigation of infertility and the low sperm density often found in patients referred for sperm banking have suggested that testicular exocrine function may be abnormal in the presence of germinal tumours before treatment. If correct, this observation might have fundamental biological importance as the germ cell line is thought to produce the stem cell of these tumours. Furthermore, pretreatment counselling would be improved if the impact of treatment was established from prospective data in individual patients. We therefore undertook a study of the quality of semen before treatment in patients with testicular tumour.

\section{Patients, methods, and results}

Freshly ejaculated semen was collected immediately before or soon after therapeutic unilateral orchidectomy from 86 men with germinal tumours of the testis. Routine analysis was performed to assess semen volume and sperm density, motility, and morphology. ${ }^{4}$ Density was measured by means of a haemocytometer chamber with visual counting.

Thirty five patients had classical seminomas and 51 non-seminomas. Control semen specimens were provided by members of the house staff and patients of a similar age admitted electively for minor surgery. All had been abstinent for two or more days, and the patients with testicular tumour denied ejaculation in the interval from orchidectomy to analysis.

The total number of sperm per ejaculate in the 86 semen samples provided by the patients with tumours was $65.5 \pm$ SEM $10.5 \times 10^{8}$. This was significantly different from the mean of $165 \cdot 2+12 \cdot 9 \times 10^{8}$ in the 101 controls. The mean in the 35 patients with seminomas $\left(60.5+11.5 \times 10^{6}\right)$ was not significantly different from the mean in the 51 patients with non-seminomas $\left(68.9+15.6 \times 10^{6}\right)$. The mean count in all the patients was not significantly different from one half of the mean in the controls. Calculations using sperm density (which does not allow for variation in volume) produced similar results.

A subpopulation of 32 of the patients with tumours (37\%) had under $20 \times 10^{6}$ sperm per ejaculate; such low values were present in only two $(4 \%)$ of the controls (table). The distribution of sperm counts in the remaining 54 patients was similar to normal. The distribution of counts was similar in patients with seminomas and those with non-seminomas.

The mean sperm count in seven patients studied before orchidectomy (45.3 $14.8 \times 10^{6}$ per ejaculate) was less than the mean after orchidectomy $\left(66 \cdot 2+11 \cdot 1 \times 10^{6}\right)$ (figure). Two patients studied before 